\title{
Prophylactic Surgery for Tethered Cord Syndrome: Early Results
}

\author{
${ }^{1}$ Dr. Nagesh Prabhakar Naik, ${ }^{2}$ Dr. Hemant Madhukar Naik., ${ }^{3}$ Dr. Deshpande \\ Shrikant Balkrishna, \\ ${ }^{l}$ MS orth; DNBorth; DNBpmr Professor, department of orthopaedics, Bharati Vidyapeeth Deemed University \\ Medical College \& Hospital, Sangli Address: P.G.Naik Memorial Accident and Orthopaedic Hospital, \\ Ambedkar Road, Near S.T.Stand, Sangli 416416 maharashtra India \\ ${ }^{2}$ M.S, M.Ch. paed.surg., Dip.N.B. paed. surg Associate professor, Department of surgery, Padmashree Vikhe \\ Patil Medical College, Ahmednagar. \\ ${ }^{3}$ M.S. orth. Associate professor, department of orthopaedics, Bharati Vidyapeeth Deemed University Medical \\ College \& Hospital, Sangli
}

\begin{abstract}
Aims \& objectives: To study results of surgery in terms of prevention of development of neurodeficit. Material \& methods: 18 paediatric cases of 6 months to 4 years during June 2007 to February 2012 who underwent MRI scanning for cutaneous stigma of spina bifida like dermal sinus, patch of hair,etc without any neurodefecit \& have low lying cord directly tethered to cutaneous lesion formed subject for study.

Patients were operated through midline incision including cutaneous lesion. Proximal lamina was removed to expose dura which was followed circumferentially in the spinal defect to develop continuity of cutaneous lesion to dural tube. Dura was opened in center proximally \& then extended distally. Tethered part is removed distal to neural structures. They are repositioned inside \& dura is sutured .

Post operatively patients are followed at six monthly intervals for appearance of neurodefecit.

Discussion: Early treatment is important because of likelihood of avoiding or reversing neurological deficit is greatest early on and decreases with age. Author believes that deficit is due to traction injury which is less likely to recover even after surgery so it is better to do prophylactically before they appear.

Results: No patient developed neurodefecit either in the postoperative period or during follow up period. which ranges from six months to three years. Long term results are awaited. Short term results are encouraging.

Key words: Tethered cord syndrome, Untethering, Prophylactic, Conus
\end{abstract}

\section{Introduction:}

Tethered cord syndrome (TCS) is defined as progressive neurological deficits from the restraint of spinal cord movement and traction due to either anatomical or physiological reasons. Tight filum terminale as a cause of tethered cord syndrome (TCS) has been known for more than 25 years and is recognized as a clinically important problem in children and adults ${ }^{1}$. TCS is a complex clinicopathological entity that remains poorly understood $^{2}$. However with the advent of MRI and present understanding of embryo genesis have led to early recognition of this syndrome in paediatric neurosurgical practice.

\section{Embryogenesis}

A diagnosis of TCS is made when the tip of the conus is below the level of L1 vertebral body. The ascent of the cord which occurs throughout the embryonic, foetal and postnatal period requires a well formed cord and a smooth meningeal covering. During retrogressive phase of secondary neurulation, the ectoderm on either side of the neural plate comes together as neural tube closes. When neural tube fusion is complete, the ectoderm detaches on either side in an event called dysjunction and fuses. If, however the dysfunction occurs before the neural tube closure is complete, or if, the closure is faulty mesenchymal cells gain access to the central canal of the neural tube .The mesenchymal cell differentiate into fatty tissue to form a lipomyelomeningocoele ${ }^{3}$. Which is essentially a mass of fat extending from the conus medullaris to the subcutaneous plane underlying an intact skin. The solitary thickened, nonresilient filum terminale occurs form defect in complex embryogenesis of filum terminale.

\section{Pathogenesis}

It is the cord which is tethered, with the nerve roots lying lax and even loosely on either side. The effects of tethering is maximum close to the site of tethering and when tethering lesion extends over a distance, the maximum effect is on the cord adjacent to the caudal end of the lesion, where the maximum stress lies. Here, it is physically elongated and functionally most affected. 
Conditions resulting in tethered cord can be classified as follows

- Anatomical: The conus is placed at a lower level than normal. During embryonic life the spinal cord is way down at the sacral segments and gradually the conus ascends and reaches the adult level to $\mathrm{L}^{4}$, as confirmed by ultrasonograhic studies in this pathological condition the spinal cord is tethered to anatomical structures lower down, preventing the ascent of conus in parallel to vertebral growth. On the other hand there is disproportionate growth between the spine and the spinal cord resulting in progressive traction ${ }^{1}$.This is evident during period of rapid growth, which explains onset of neurological abnormalities at that time.

- Physiological: This is due to tight or thick filum. In this variety the conus may be at normal level but the movement of the cord is restrained. Normally, when the child bends forward, is an ascent of cord by one to two segments which is prevented by tight filum. Acute deterioration may follow following acute flexion of spinal column, as reported by Pang and Wilberger ${ }^{5}$. The resulting neurological deficit and neurological dysfunction are called "non neurogenic bladder".

- Developmental: This could be secondary to a variety of conditions like congenital anomalies, terminal lipoma, intraspinal lipoma, lipomyelomeningocoele ${ }^{6}$, split cord malformations, sacral agenesis, and other occult dystrophic states.

- Postoperative: Even after initially successful untethering procedure, many patients exhibit radiological evidence of adhesion of the residual lipoma to dural $\mathrm{sac}^{7}$. Literature proposes following precautions. This includes complete untethering of all the contributory structures, proper concealing of rough and adhesive surfaces by 8-0 pial sututres, laminectomy to accommodate thickened cord, and to facilitate upward movemnt, duraplasty too create a reservoir of CSF around the repaired structures, epidural fat grafts to prevent fibrosis, and nursing the child in prone position postoperatively.

- Mechanism of neurological deterioration:

- With ongoing stretching central fibers are subjected to traction injury resulting in structural damage.

- Mechanical stretching during physical activity leads to changes in intracellular respiration, reduction in cytochrome oxidase and shift in redox curves ${ }^{8}$

- Traction can compress radial perforating vessels leading to ischaemic damage of $\operatorname{cord}^{9}$

\section{Diagnosis:}

The diagnosis is based on high index of suspicion

Neurological examination: Neurocutaneous markers like tuft of hair, nevus, dysplatic skin, angiomatous pathches, lipoma, dermal sinus, presence of human tail and absence of gluteal folds are strong indicators. Neurovasical dysfunction, leg pain, scoliosis, motor or sensory deficits, should prompt the clinician to look for tethered cord even in absence of Neurocutaneous markers. ${ }^{10,11}$

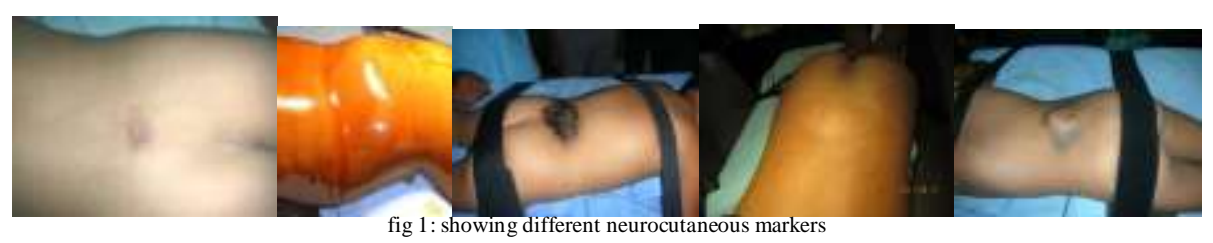

Tethering being a congenital phenomenon, these children often present to their paediatricians, with vague leg pains; to orthopaedicians with gait disturbance and deformities, to urologists and paediatric surgeons with bladder symptoms ,frequent or persistent bed wetting and finally to neurosurgeons when the neurological deficits become overt. Hence awareness about this syndrome in medical fraternity is necessary.

MRI is the choice of investigation to identify the location of conus and associated abnormalities. The classical dorsal displacement of conus with a large ventral CSF space is often suggestive.

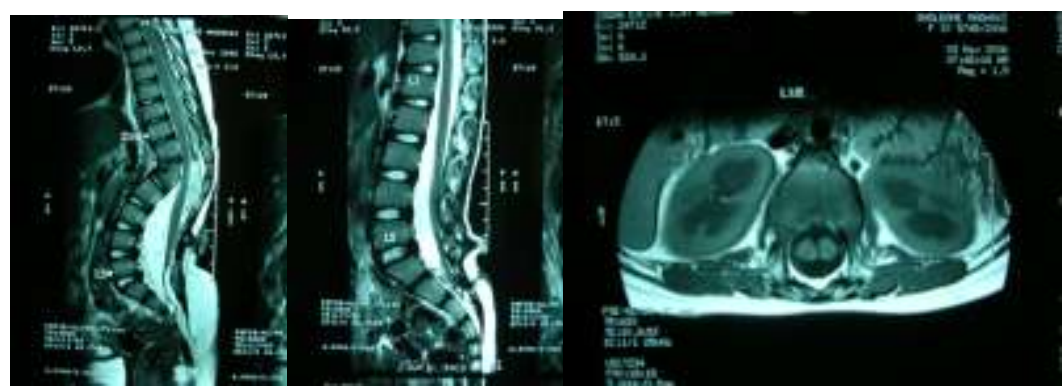

Fig 2 : MRI appearance of tethered cord 
Early appearance of lumbar potentials in SSEP has been found valuable ${ }^{12}$.

\section{Materials And Methods}

From June 2007 to February 2012,18 patients with TCS with no neurological deficit were treated at Naik Paediatric Surgery Center, Ahmednagar. Clinical characteristics, radiological features and surgical outcome were evaluated by prospective analysis. As criteria for inclusion in this study is "no neurological deficit", the diagnosis was based only on Neurocutaneous markers which apprehended parents to approach paeditrician which in turn referred patients to paediatric surgeon. All patients underwent MRI scanning to identify the location of conus and associated abnormalities. The classical dorsal displacement of conus with a large ventral CSF space is often suggestive. No patient underwent SSEP The age group was from six months to four years. These patients were divided into two groups according to age: group A, less than three years old; group B, more than three years old. For assessment of surgical outcome patients were graded as clinically improved, stable, mildly changed (only mild voiding difficulty postoperatively), and worsened.

All the patients were operated at one center and by one surgeon and the operative procedure were mostly consistent in this series as follows. Patient was operated under general anaesthesia with endotracheal intubation in prone position. Midline incision with elliptical inclusion of cutaneous lesion was taken. In the proximal part of incision the paraspinal muscles were retracted off the spinous process to expose proximal lamina The skin lesion was followed circumferentially to the same depth carefully. Proximal lamina was removed to expose the dura. With the help of dura retractor and Kerrison forceps the laminectomy was followed distally circumferentially around the lesion till continuity of lesion to dural sac was achieved from all sides. At this stage dura was opened in midline proximally and extended distally to the tether. Dura is cut circumferentially as distally as possible so that maximum amount of dura will be available for closure of sac. At this point continuity of tether to conus with lax nerve root hanging anteriorly was exposed. Tethered part was removed distal to neural structures under loupe magnification. Good haemostasis was achieved with patties. Filum terminale was cut when it was found thickened and stretching conus. Dura was closed with 5-0 vicryl sutures. Paraspinal muscles were approximated with 2-0 vicryl interrupted sutures over a closed suction drain. Release of paraspinal muscles from both sides was done at the level of skin lesion where approximation was difficult and tight. Skin was sutured with interrupted 3-0 ethilon sutures.

The child was nursed in prone position, and the wound was protected form faecal and urinary contamination. Drain was removed at 48 hours. The sutures were removed at ten days and patients were discharged. Follow up was done at three months and then at six monthly intervals. Patients were communicated on phone to know any problems. Pial sutures, duraplasty and epidural fat graft was not done in any patient No patient underwent pre or postoperative urodynamic studies. No patient underwent follow up MRI

\section{Observations}

The patient population was made up of 10 males and 8 females. There were 12 patients under 3 years old(group A) and 6 over 3 years old(group B). The median follow up was 2.5 years (range 6 months to 5 years)

Table 1:Age distribution of 18 patients of TCS

\begin{tabular}{|l|l|}
\hline Age distribution & Number of patients \\
\hline Birth to 1 month & 0 \\
\hline 2-6 months & 0 \\
\hline $7-12$ months & 5 \\
\hline 13 months to 3 years & 7 \\
\hline More than 3 to 4 years & 6 \\
\hline
\end{tabular}

Patients were referred only on the basis of Neurocutaneous markers.

Table 2: distribution of neurocutaneous markers in 18 patients of TCS

\begin{tabular}{|l|l|}
\hline Neurocutaneous markers & Number of patients \\
\hline Tuft of hair & 8 \\
\hline Nevus & 0 \\
\hline Dysplastic skin & 1 \\
\hline Angiomatous patches & 2 \\
\hline Lipoma & 6 \\
\hline Dermal sinus & 2 \\
\hline $\begin{array}{l}\text { Presence of human tail and } \\
\text { absence of gluteal folds }\end{array}$ & 0 \\
\hline
\end{tabular}


Postoperatively all the patients remained stable during follow up. No patient deteriorated neurologically in immediate postoperative period or in follow up.

As none of the patients developed neurodeficit, there was no difference between group A and group B as far as results were concerned Cutting of thickened filum terminale was necessary in 11 patient while lateral release for approximation of spinal cord was needed in 8 patients..Complications related to operation were superficial gaping of wound in one case which healed with resuturing. No patient had CSF leak or newly developed neurodeficits. None of the patients required reoperation because of subsequent symptomatic retethering.

The surgical outcome was satisfactory in terms of nondevelopment of neurodeficit in available follow up

\section{Discussion}

Knowing the mechanism of neurological deterioration prophylactic surgery is logical. Without therapy or with inappropriate therapy, the neurological function deteriorates with increasing age and finally the patient becomes incapacitated. Fixation and/or tethering of spinal cord and nerve roots are undoubtedly the major causes of worsening. Hoffman et $\mathrm{a}^{13}$ have stressed the importance of early treatment of TCS patients, because the likelihood of avoiding or reversing a nerurological deficit by surgical treatment is greatest early on and decreases with age, presumably indicating that with delayed treatment chronic traction on spinal cord ultimately leads to irreversible deficits. MCLone et $\mathrm{al}^{14}$, Lamarc et $\mathrm{al}^{15}$ and Herman et $\mathrm{al}^{16}$ and Joon-Kin Kang et al ${ }^{17}$ have also recommended early surgical intervention for lipomeningomyelocoele. In agreement with these authors we advocate repair of these lesions as soon as they are detected in patients referred after 1-6 months.

Balsara et $\mathrm{a}^{18}$ report that early operative intervention leads to good outcome and that younger patients tend to improve more than older patients. Joon-Ki Yang, et $\mathrm{al}^{17}$ in his series showed less neurological deterioration in patients less than 3 years of age.As none of the patients developed neurodeficit either in postoperative period or during follow up, there was no difference between Group A and Group B, however the number of patients is too small and the duration of follow up is less to compare with series of Joon-Ki Yang et $\mathrm{al}^{17}$ to decide statistical significance of conclusion.

The aims of surgery in this study was to untether the cord \& resect as much as lipoma as possible without injury to cord and nerve root. In addition it is important to restore dural sac to prevent postoperative retethering and to maintain a normal CSF circulation space. Joon-KI yang et $\mathrm{al}^{17}$ attempted pial suture with megadural grafting with good results. In present series dura was cut as distally as possible while circumferentially cutting dura around tether so that maximum amount of tissue will be available for closure and proximal laminectomy was helpful to accommodate conus inside dura. Apart from this no other procedure was done. As none of the patients developed neurodeficits in follow up, none of them underwent repeat MRI. However further long term follow up \& repeat MRI is necessary to come to definitive conclusion though early results are encouraging.

Joon-Ki Yang et al ${ }^{17}$ reported postoperative complications CSF leakage(6.5\%),new development of neurodefecit $(8 \%)$ and reoperation for retethering (5.3\%). In present series apart from superficial gaping in one patient $(5.5 \%)$ other complications did not occur however the number of patients is small to compare to abovementioned series.

\section{Conclusion}

Our data continue to support the literature opinion that early diagnosis and adequate release of tethered cord are of key importance to successful management of patients with tethered cord syndrome. High index of suspicion is necessary to catch hold of patients before neurological symptoms appear. Well performed prophylactic surgery is definitely helpful for these patients. Importance of proximal laminectomy and cutting of dura as peripherally as possible in an attempt to prevent retethering cannot be underemphasized. Though early results are encouraging, further long term follow up and repeat MRI are planned in further part of the study to come to definitive conclusion.

\section{References}

[1] Huttmann S,Krauss J, Collmann H, Sorensen N, Roosen K,: Surgical management of tethered spinal in adults: report of 54 cases. J Neurosurg 95(Suppl 2):173-178,2001

[2] Yamada S, Zinke DE, Sanders D: Pathophysiology of"tethered cord syndrome” J. Neurosurg :54:494-503,1981

[3] Pang D. sacral agenesis and caudal spinal malformation.Neurosurgery.32:755-78:1993

[4] Hoffman HJ, Hendrick EB, Humphreys RP: The tethered spinal cord its protean manifestations, diagnosis and surgical correction Childs Brain 2:145-155,1976

[5] Pang D, Wilberger JE,: Tethered cord syndrome in adults:J. Neurosurg 57:32-47,1982

[6] Gupta DK, Ramdurg S,Mahapatra AK,. Giant terminal lipomyelocystocoele Pediatr. Neurosurg.42:49-53:2006

[7] Sakamato H, Hakuba A, Fujitani K, Nishimura S :Surgical treatment of the retethered spinal cord after repair of lipomeningocele J Neurosurg 74:709-714,1991

[8] Yamada S, Lacono RP, Andrade T, Mandibur G, Yamada BS: .Pathophysiology of the tethered cord syndrome Neurosurg. Clin. N. Am 6:311-323,1995 
[9] Kanev PM,Lemire RJ, Loser JD, Berger MS: Management and long term follow up review of children with lipomyelomeningocele,1952-1987. J. Neurosurg 73:48-52,1990

[10] Capitanucci ML, Iacobelli BD, Silveri M,et al.Long term urological follow up of occult spinal dysraphism in children. Eur. J. Pediar. Surg,6(suppl 1): 25-26, 1996

[11] Chakarabortty S, Oi S, Yoshida Y, et al. Myelomeningocele and thick filum terminale with tethered cord appearing as a human tail. Case report.J Neurosurg.: 78:966-969,1993

[12] Breig A. Overstretching of and circumscribed pathological tension in the spinal cord: a basic cause of symptoms in cord disorders, $\mathbf{J}$ Biomech:33,7-9,1970

[13] Hoffman HJ, Taecholarn C.Hendrick EB, Humphreys RP: Management of lipomeningoceles. Experience at hospital for sick children, Toronto. J. Neurosurg. 62:1-8,1985

[14] McLone DJ, Mutluer S, Naidich TP: Lipomeningoceles o fthe conus medullaris. In :Raimondi AJ(ed)Concepts in paediatric neurosurgery, vol 3, Karger, Basle, 170-177,1983

[15] Lamarca F, Grant JA, Tomita T, McLone DG: Spinal lipoma in children-outcome of 270 procedures Pediatr Neurosurg 28: 816,1997

[16] Herman JM, McLone DG, Store BB, Dauser RCL Analysis of 153 patients of myelomeningocele or spinal lipoma reoperated upon for a tethered cord:Pediatr. Neurosurg. 19;243-249,1993

[17] Joon-Ki Kang, Kwan-Sung Lee, Sin-Soo Jeun, et al: Tethered cord syndrome;surgical indication, technique and outcome: J Korean Neurosurg Soc 42;77-82,2007

[18] Bulasara KR, Zomorodi AR, Villavicencio AT, Fuchs H, George TM: Clinical outcome differences for lipomyelomeningoceles, intraspinal lipomas, and lipomas of the filum terminale. Neurosurg Rev 24: 192-194, 2001 